\title{
AN INVESTIGATION INTO LUBRICATION AND OXIDE BREAKDOWN DURING LOAD CARRYING CAPACITY TESTING
}

\author{
Vivian P. Möller \& Philip L. de Vaal \\ Department of Chemical Engineering, University of Pretoria, Pretoria, South Africa
}

\section{Synopsis}

Changes occurring in the friction and wear mechanisms during a load carrying capacity test, lubricated with cetane containing a carboxylic acid, were investigated. The changes in wear scar /track appearance and oxide coverage/composition were analysed during every load stage. The main conclusions were:

- The breakdown in the protective oxide layer formed on the opposing steel surfaces was found to be the pre-requisite for initiation of seizure.

- The seizure load achieved during load carrying capacity testing quantifies the ability of the test fluid to prevent transition to the adhesive wear regime.

- The most severe surface damage was found to occur during the first few seconds after test initiation. Desorption of the adsorbed lubricant film and the subsequent removal of the naturally occurring thin oxide layer results in the initial period of adhesive wear.

- Partial recovery to a state of acceptable friction occurs after the period of initial seizure. During this period the surface coverage by the adsorption lubricant molecules and the oxide coverage are sufficient to prevent severe adhesive wear from occurring. 
Wear is primarily a combination of oxidative, abrasive and fatigue wear (all possible in the regions of mixed friction and boundary lubrication).

- Final lubricant breakdown and eventual seizure is initiated when the oxide removal rate exceeds the oxide formation rate resulting in severe adhesive wear followed by seizure.

Keywords: SRV-machine, Load Carrying Capacity, Oxide layer 


\section{INTRODUCTION}

The physical significance of the term lubricity is best described by the definition formulated by Appeldorn \& Dukek (1966) "If two liquids have the same viscosity, and one gives lower friction, wear or scuffing, it is said to have better lubricity." Lubricity is a term used specifically to refer to the lubricating properties of fuels. The primary role of a fuel is not that of a lubricant and therefore does not possess the properties typically found in fluids designed specifically for lubricating contacting surfaces. Lubricity has however become an increasingly important fuel property for petroleum refiners and engine manufacturers, specifically with regard to diesel. More stringent environmental legislation regarding motor vehicle emissions and the introduction of high pressure common rail diesel injection technology have placed more stringent demands on diesel lubricity (Margoni, 1998). To obtain more complete combustion, finer atomization of the fuel is required. In order to fulfil this objective, internal engine operating pressures have increased therefore increasing the loading between the injector plunger and body (Qu et al., 2007). The lubricity of the diesel fuel therefore plays a critical role in ensuring that the injection system is adequately lubricated. Lubricity has been well researched by Appledorn and Dukek (1966), Wei \& Spikes (1986) and Wei et al.(1999) and still remains a prominent research topic. With the current drive towards the incorporation/use of first generation biodiesel in modern diesel engines, the lubricity of biodiesel has also been extensively researched in recent years. Oguz et al. (2011) investigated the lubricating performance of biodiesel produced from safflower, cotton seed, soybean and sunflower oil on a pin-on-disk tribometer. The effects of E100 biodiesel on the injector and pump wear was investigated by Celic \& Aydin (2011) by using scanning electron microscopy (SEM) and energy-dispersive X-ray spectroscopy (EDX). 
Lubricity is quantified using lubricity bench tests. Load carrying capacity and wear testing are two types of lubricity bench test used to quantify the lubricity of a test fluid.

The correlation between wear and seizure load testing was investigated by Lizoe et al.(2009). In their study, the correlation between the humidity corrected wear scar diameter (WS 1.4) and load carrying capacity (for ultra low sulphur diesel containing different additives) was investigated using the High Frequency Reciprocating Rig (HFRR) and the High Temperature Oscillating Machine (HiTom). Good correlation between the HiTom seizure load and HFRR WS 1.4 was found for the additives investigated. The Optimol SRV®4 (SRV - A German acronym for oscillation, friction and wear) is another type of tribometer that has been utilized to conduct a load carrying capacity test for diesel fuel. The SRV is utilized in an in-house developed diesel load carrying capacity (LCC) test. The test was developed in 1988 in the Tribology Laboratory of Department of Chemical engineering at the University of Pretoria. The correlation between the HFRR and the SRV-LCC test was however found to be highly dependent upon the composition of the fuel investigated. Poor correlation between wear and seizure load tests was observed with fuels possessing a high SRV load carrying capacity performing poorly on the HFRR and vice-versa. The two types of test method may therefore correlate well for certain additive/base fuel combinations and show no correlation for other additive/base fuel combinations. In this work it is shown that the distinction between the two test methods is due to the difference in the friction, wear and boundary lubrication mechanisms applicable to the two different test methods. A fundamental understanding of the roles of the boundary lubricant additive, oxygen and the carrier fluid is critical to gain an understanding of the differences that 
are observed between wear and load carrying capacity test results for certain test fluids. To this end, a simplified system resembling the properties of fuel was used.

The load carrying capacity of a fuel characterizes the ability of the fuel to prevent seizure from occurring in a highly loaded contact. Seizure is characterized by the breakdown in lubrication resulting in the sudden, unexpected transition of a contact to the adhesive wear regime during which the contacting surfaces are severely damaged (Lee \& Cheng, 1991), (Bowman \& Stachowiak, 1996). Load carrying capacity testing performed on a number of test rigs like the Optimol SRV, uses a top specimen that is moved (uni- or bi-directionally) against a bottom specimen with the contact area immersed in the test fluid while the normal load is increased in a specific sequence. The load at which seizure occurs serves as the parameter used to quantify the load carrying capacity of the test fluid.

The main objectives of this investigation were to gain a fundamental understanding of the wear and friction mechanisms and of the change in oxide coverage during a SRV diesel load carrying capacity test.

To minimize unknown chemical interactions, $\mathrm{n}$-hexadecane (cetane) was used as the base fluid. Palmitic acid was used as adsorption lubrication additive.

The lubrication, wear and seizure mechanisms as well as oxide composition and the extent of coverage were investigated by performing an interrupted seizure load test. The wear patterns were investigated using optical microscopy. The oxide coverage, composition and mechanism of seizure were investigated using Raman spectroscopy. 


\section{EXPERIMENTAL}

As test fluid, n-hexadecane (for synthesis, with purity > $99 \%$ ) was used. n-Hexadecane is a straight chain paraffin with no lubricating ability and boiling point in the range of diesel fuel. Palmitic acid was used as adsorption lubricant additive. Palmitic acid is a 16-carbon straight chain carboxylic acid. A single concentration of $2000 \mathrm{mg} / \mathrm{l}$ palmitic acid in n-hexadecane was used for all testing. This concentration of palmitic acid ensured adequate performance of the fluid for purposes of this study.

The Optimol SRV@4 apparatus was used to conduct a diesel load carrying capacity (LCC) test. An oscillating ball on stationary disk configuration was used with the test fluid being fed continuously throughout the test in a drip-wise manner. A schematic indicating the specimen arrangements and SRV operating principle is shown in fig. 1. The test parameters used are listed in table 1.

A block (the platform on which the stationary specimen rests during the test) temperature of $110^{\circ} \mathrm{C}$ was maintained throughout the test. This condition correlates well with the temperatures found in the injection systems of modern automotive engines. The test fluid was entrained using a grooved copper ring with excess fluid overflowing into a waste flask. A schematic of the feed system can be seen in fig. 2 . The fluid is therefore continuously replenished throughout the test to ensure that during the test, as few parameters as possible are changed. The continuous flow arrangement therefore maintains the fluid properties and composition as constant as possible during a test which is not possible with a once-off volume of test fluid. No concentration of species occurs due to evaporation of the carrier fluid at the test conditions. The continuous flow 
arrangement also represents the practical application, e.g where diesel flows through an injection system.

The seizure criterion for the test, as indicated in table 2.1, is reached when the friction coefficient of 0.3 is exceeded. The choice of a coefficient of 0.3 is to a large extent arbitrary, but was chosen to indicate metal-to-metal contact, based on the fact that the static friction coefficient for hard steel on hard steel is 0.78 (on a dry contact) and the dynamic friction coefficient for hard steel on hard steel (on a dry contact) is 0.47 (Szeri, 2005). The lubricated coefficient of friction for hard steel on hard steel is about 0.1 . It is therefore reasonable to assume that, during a lubricated test, where the coefficient of friction is of the order 0.1 that a sudden increase in the coefficient of friction to 0.3 can be regarded as a consistent indication of breakthrough or direct metal-to-metal contact.

\section{Friction and Wear Mechanism and Oxide Structure}

The different wear regimes and lubrication mechanisms were studied by performing a load carrying capacity test with the test fluid described in the introduction of section 2 . A profile was therefore generated for the change in friction coefficient vs. test duration (seconds) and normal $\operatorname{load}(\mathrm{N})$ 
The wear mechanism and oxide layer breakdown were analysed by performing an interrupted load carrying capacity test. The test is performed by stopping the test at every load stage, removing the test specimen and analysing the ball scar and wear track on the bottom disk. The wear scar is the worn area generated on the surface of the ball due to sliding. The wear track is the worn area formed on the disk due to sliding. Fresh test fluid is used during each run of the interrupted load carrying capacity test. To investigate the wear mechanism, the Mean Wear Scar Diameter (MWSD) and wear scar appearance were measured using optical microscopy. The oxide composition and coverage were investigated using Raman spectroscopy. The Raman spectra were recorded with a T64000 micro-Raman spectrometer from HORIBA Scientific, Jobin Yvon Technology (Villeneuve d'Ascq, France). The Raman spectra were excited with the $514.6 \mathrm{~nm}$ line of a Coherent Innova ${ }^{\circledR} 70 \mathrm{C}$ Series Ion Laser System and the 100x objective of an Olympus optical microscope was used to focus the laser beam (spot size $\sim 2-4 \mu \mathrm{m}$ ) on the samples and also collected the backscattered Raman signal. An integrated triple spectrometer was used in the double subtractive mode to reject Rayleigh scattering and dispersed the light onto a liquid nitrogen cooled Symphony Charged-Coupled Device (CCD) detector. The spectrometer was calibrated with the silicon phonon mode at $520 \mathrm{~cm}^{-1}$.

\section{Lubrication Breakdown and Seizure}

Failure during the SRV - LCC test occurs when the friction coefficient exceeds a value of 0.3. Seizure has been suggested to be initiated when sufficient metal to metal contact occurs (Batchelor \& Stachowiak, 1986). Removal of the protective oxide layer, formed due to high interfacial temperatures between the contacting surfaces, is therefore an important prerequisite 
for seizure to occur. Raman spectroscopy was used to identify areas which were free of a detectable oxide layer.

\section{RESULTS AND DISCUSSION}

\section{Lubricating Regime and Lubrication Mechanism}

Due to the low viscosity of the carrier fluid (cetane), the contact geometry (oscillating ball-ondisk) and the relatively slow sliding speed $(0.05 \mathrm{~m} / \mathrm{s})$ the contact operates primarily in the boundary lubrication regime. Asperities from opposing surfaces are therefore in contact. The primary boundary lubrication mechanism at work in the contact, is adsorption lubrication. Typical adsorption lubricants are long chain, polar, organic molecules capable of adsorbing to the polar oxide surface therefore providing a plane of lower resistance between the contacting surfaces along which sliding can occur (Batchelor \& Stachowiak, 2005:360). The presence of an oxide layer is critical for effective boundary lubrication (Batchelor \& Stachowiak, 2005:369). The oxide layer provides a catalytically inactive, hard, low-adhesion platform for adsorption lubricants to adhere to. It was found (Morecroft, 1971) that the nascent metal surface is highly reactive and will result in the catalytic decomposition of organic molecules coming into contact with it. Primary oxides found in stainless steel frictional contacts, such as was the case during this investigation, are magnetite $\left(\mathrm{Fe}_{3} \mathrm{O}_{4}\right)$ and hematite $\left(\mathrm{Fe}_{2} \mathrm{O}_{3}\right)$ (Crocket et al., 2004). Hematite is red in appearance, hard and abrasive. Magnetite has a black appearance and is soft and a good solid lubricant (Cameron, 1981:207). 
Raman spectroscopy is a very useful surface analytical technique that has been used successfully to determine the presence of different oxide species generated in frictional contacts (Olah et al., 2005) and (Crocket et al., 2004).

Raman spectroscopy was used by Lubbe et al. (2010) to study thin films (22-48 nm) of hematite and magnetite grown on $\mathrm{Al}_{2} \mathrm{O}_{3}$. From the research conducted by Lubbe et al. (2010) and Hongyi et al. (2013) it is shown that Raman spectroscopy is indeed a very sensitive surface analytical technique that can be used to study thin films of magnetite and hematite. The sensitivity will however differ from one spectroscope to another. To quantify and verify the observations made regarding the change in oxide thickness, a calibration test must be performed to determine the change in peak intensity with hematite and magnetite oxide thickness. The minimum detectible oxide thickness must also be quantified.

The characteristic peaks for magnetite and hematite were reported by Colomban et al. (2007). In this study, the primary use of Raman spectroscopy was for the identification of the different metal oxide species.

Under sliding conditions, the increase in surface temperature will result in an increase in the rate of desorption of the adsorbed boundary lubricant (Grew \& Cameron, 1972). This phenomenon occurs when the surface temperature exceeds the critical desorption temperature of the adsorbed lubricant (Batchelor \& Stachowiak, 2005:376). An increase in the lubricant hydrodynamic film pressure will however result in a significant increase in the critical desorption temperature. When a contact operates in the boundary lubrication regime, the lubricant pressure is negligible due to the absence of any significant hydrodynamic lifting action (Lee \& Cheng, 1991). 
The surface is however covered with asperities with a length of several microns (Batchelor \& Stachowiak, 2005:449). From a microscopic perspective, the asperities are covered with adsorbed boundary lubricant molecules. As two asperities collide, the flash temperature increase will result in a rapid increase in the asperity temperature (Block, 1952) causing the adsorbed molecules to be desorbed if temperature exceeds a certain value for a period of time (Spikes \& Cameron, 1971). An increase in relative sliding speed, normal load or friction coefficient will result in an increase in the temperatures at the asperity tips (Block, 1972) therefore increasing the rate of desorption and lowering the surface coverage.

The adsorbed lubricant surface coverage will influence the rate of oxidative wear in the contact. As the surface coverage decreases, the rate of oxide removal will increase. Due to the change in contact temperature, the rate of oxide formation will also be affected (Batchelor \& Stachowiak, 1986).

\section{Friction and Wear Profile}

In fig. 3 and fig. 4, the friction coefficient and mean wear scar diameter (MWSD) profiles are shown. The MWSD was measured by stopping the test at different intervals allowing the wear scar to be measured and the appearance captured. The following transitions were identified on the friction coefficient and MWSD profiles:

- Initial seizure, designated A.

- Partial recovery to low friction and mild wear conditions, designated B.

- Period of mild wear and low constant friction, designated C. 
Breakdown of adsorbed lubricant film and removal of oxide layer leading to eventual seizure, designated D.

The following different stages can be distinguished on the friction coefficient vs time and MWSD vs time profiles:

\section{Initial Seizure}

From fig. 3, it can be seen that the friction coefficient remains low for the first approximately two seconds after test initiation after which the friction coefficient increases rapidly to a value of 0.55 during the following approximately 3 seconds. In fig. 4 it can also be seen that very high wear results with the MWSD increasing from 0 to $410 \mu \mathrm{m}$ over the first 5 seconds after test initiation.

The lowest value in wear rate and friction coefficient observed during the first 2 seconds can be attributed to the adsorbed film being at the maximum coverage during test initiation. The coverage of the initial film however rapidly decreases during the first 100 oscillations (approximately 2 seconds) causing the friction coefficient and wear rate to increase sharply leading to seizure as can be seen in fig. 3 and 4. As oscillation is initiated, the surface temperature rapidly increases resulting in desorption of the adsorbed palmitic acid molecules. As the surface coverage decreases, the rate of oxide removal rapidly exceeds the rate of oxide 
formation resulting in the formation of nascent metal surface. From fig. 5, the Raman spectra of the wear scar and track obtained after 5 seconds of sliding, it can be seen that no peaks can be detected, indicating that the oxide layer is either very thin or absent and beyond the detection level of the Raman spectrometer used.

Intimate contact between the nascent metal surface on the top and bottom specimens results in the formation of metallic bonds. The high wear can be attributed to adhesive wear being the dominant wear mechanism during the first 5 seconds after test initiation. Fatigue and oxidative wear resulting in two and three body abrasive wear is most likely also present during the first 5 seconds as is proven by the severe abrasive wear marks observed on the wear scar surface after 5 seconds as shown in fig. 6 .

\section{Partial recovery after initial seizure}

The re-establishment of a low friction coefficient is a complex process involving several critical processes occurring in parallel. It can however be reasoned that the re-establishment of conditions of low friction and mild friction proceeds by the following steps. The increase in interfacial temperature at the asperity tips results in the oxide formation rate exceeding the oxide removal rate. The increase in actual contact area aids in lowering the oxide removal rate. A decrease in temperature at the asperity tips occurs due to the reformation of the oxide layer and an increase in the real area of contact. This explanation is experimentally substantiated by the Raman spectrum obtained after 10 seconds on the wear scar surface, shown in fig 7. 
From fig. 7 it can be seen that a layer of hematite (peaks designated A) has been formed after 10 seconds. The presence of amorphous carbon can also be observed (peaks designated B) (Colomban et al., 2007) which may have been caused by the catalytic decomposition of the adsorption lubricant/carrier fluid at very high temperatures.

A decrease in temperature and the elimination of nascent metal surface by reformation of the interfacial oxide layer at the asperity tips allow the palmitic acid molecules to be re-adsorbed at the asperity tips. The oxide layer reaches full surface coverage. Wear occurs by mild oxidative, fatigue and abrasive wear.

\section{Period of mild oxidative, fatigue and abrasive wear}

In fig. 8 and fig. 9, the change in wear scar and track appearance can be seen for an increase in normal load from $50 \mathrm{~N}$ to $250 \mathrm{~N}$. In fig. 4, it can be seen that the MWSD only undergoes a slight, gradual increase during the increase in normal load from $50 \mathrm{~N}$ to $250 \mathrm{~N}$. From fig. 8 and fig. 9 it can be observed that the wear scar and track appearances also remain relatively consistent during this period of the test. Distinct abrasion marks are clearly visible on the wear scar and track throughout the test. 
During this period, wear is mild as can be seen from the gradual increase in MWSD. During this period surface coverage by the palmitic acid molecules and the oxide are sufficient to prevent severe adhesive wear from occurring.

During each step increase in normal load, a combination of the following events may occur:

- The temperature at the asperity tip increases.

- The area where the critical desorption temperature is exceeded increases, accompanied by the desorption of adsorbed palmitic acid molecules from these specific areas. A decrease in adsorption lubricant surface coverage therefore occurs.

- The decrease in adsorption lubricant surface coverage increases the rate of oxide removal. The rate of oxide formation still exceeds the rate of oxide removal therefore preventing the formation of nascent metal surfaces. Wear therefore occurs by a combination of mild oxidative, fatigue and abrasive wear.

\section{Oxide and Lubricant Film Breakdown and Seizure}

As the normal load increases, the increase in interfacial temperature at the asperity tips results in the further decrease in adsorption lubricant surface coverage. The balance between oxide formation and oxide removal is also subsequently influenced by the change in palmitic acid surface coverage with the rate of oxide removal being increased by the decrease in adsorbed palmitic acid surface coverage. This explanation is strongly supported by the Raman analysis performed on the wear scar at $300 \mathrm{~N}, 350 \mathrm{~N}$ and $400 \mathrm{~N}$. In fig. 10, the change in wear scar appearance from $300 \mathrm{~N}$ to seizure at $400 \mathrm{~N}$ can be seen. 
The Raman analysis of the wear scar obtained at 300 N, shown in fig. 11, reveals the light, grey and dark areas having the following composition:

- Light: Free of detectable oxide.

- Grey: Hematite (peaks A) and magnetite (peak C).

- Dark: Magnetite and amorphous carbon (peaks B)

From the change in wear scar appearance, it can be seen that an increase in the light area occurred from $300 \mathrm{~N}$ to $400 \mathrm{~N}$. The same trend can also be observed for the change in wear track appearance, shown in fig. 12 .

The above-mentioned results support the explanation that the surface coverage decreases with increasing load resulting in an increase in oxide removal rate.

At $400 \mathrm{~N}$, critical surface coverage is reached. At this point the oxide removal rate exceeds the oxide formation rate causing the formation of sufficient nascent metal surface to initiate seizure. This explanation is experimentally substantiated by the appearance of the wear scar and track, shown in fig. 14 and the associated Raman spectra shown in fig. 14.

A - Peaks representing the presence of hematite 
C - Peak representing the presence of magnetite

B - Peaks representing the presence of amorphous carbon

From fig. 14, the light, oxide-free area is clearly visible on the wear scar and track. The oxidefree area therefore represents where metallic bonding occurred causing a drastic increase in friction (fig. 3) and wear rate (fig. 4).

\section{CONCLUSIONS AND RECOMMENDATIONS}

The following wear and friction regimes were identified during seizure load testing,

- Initial seizure: During test initiation, the contact undergoes a period of initial seizure which lasts for $1-2$ seconds. The initial seizure is caused by the rapid desorption of the adsorbed palmitic acid film and the subsequent removal of the oxide layer which results in the formation of nascent surface. Adhesive wear is the dominant wear mechanism resulting in a high wear rate.

- Partial recovery: After initial seizure, an increase in contact area and oxide formation rate allows re-adsorption of the palmitic acid molecules therefore re-establishing low friction and mild fatigue and abrasive wear conditions.

- Period of mild oxidative wear and low friction: During this period surface coverage by the palmitic acid molecules and the oxide is sufficient to prevent the severe adhesive wear from occurring. Wear is primarily a combination of oxidative, fatigue and abrasive wear. 
- Transition to seizure: At this point the oxide removal rate exceeds the oxide formation rate causing the formation of sufficient nascent metal surface to cause severe adhesive wear and subsequent seizure.

- From the transition occurring during the seizure load test, it can be concluded that seizure load is dependent on the ability of the carboxylic acid to prevent the removal of the oxide layer which results in the formation of nascent metal surface and eventual seizure.

- During wear testing, the load carrying capacity of the test fluid should play the most important role to reduce the initial severe adhesive dominated wear (first 10 seconds after test initiation) period during which the oxide layer is thin and still growing towards reaching full surface coverage and critical thickness. In this investigation it was shown that load carrying capacity is highly dependent on the initial conditions with the most severe wear occurring during test initiation after which a combination of protective actions are initiated - one due to the actions of the polar carboxylic acid and the other due to the formation of a protective metal oxide layer. 


\section{REFERENCES}

- Appledorn, J.K and Dukek, W.G (1966), “Lubricity of jet fuel”, SAE Technical Paper 660712

- Batchelor, AW, Stachowiak, GW (2005), "Engineering Tribology $2^{\text {nd }}$ Edition",Butterworth Heinemann

- Batchelor, AW and Stachowiak, GW (1986), "Some Kinetic Aspects of Extreme Pressure Lubrication" Wear, Vol. 108, pp. 185-199.

- Bowman WF, Stachowiak GW (1996), "A review of scuffing models" Tribology Letters, Vol. 2, pp.113-131

- Blok H (1963), "The Flash Temperature Concept" Wear, Vol. 6, pp. 483-494

- Cameron, A (1981), “Basic Lubrication Theory, $3^{\text {rd }}$ Edition” Ellis Horwood Limited, Wiley \& Sons Inc., New York

- Celic I, Aydin (2011), "Effects of B100 Biodiesel on Injector and Pump Piston" Tribology Transactions, Vol. 54, pp. 424-431.

- Colomban P, Froment F, Tournieé A (2008), “Raman identification of natural red to yellow pigments: ochre and iron-containing ores" Journal of Raman Spectroscopy, Vol. 39, No. 5, pp. 560-568.

- Crockett RM, Derendinger MP, Hug PL and Roos, S (2004), “Wear and electrical resistance on diesel lubricated surfaces undergoing reciprocating sliding” Tribology Letters, Vol. 16, No.3, pp.187-194. 
- Grew WJS, Cameron A (1972), “Thermodynamics of Boundary Lubrication and Scuffing" Proceedings. of the Royal Society of London, Vol. 327, No.1568, pp. 47-59.

- Mi H, Mikael S, Allen T, Sridharan K, Butt D, Blanchard JP (2014), “Monitoring the oxidation of nuclear fuel cladding using Raman spectroscopy” Journal of Nuclear Materials 445 pp. 7-11

- Lee HS, Cheng HS (1991), "Scuffing Theory Modelling and Experimental Correlations" Journal of Tribology, Vol. 113, pp.327-334

- Litzow U, Matzke M, Jess A, Caprotti R, Balfour G (2009), ”Diesel Lubricity Requirements of Future Fuel Injection Equipment" SAE Paper No. 2009-01-0848

- Lin, BH, Shen BX, Zhao JG (2011), “A Study on the Prediction Model for the Lubricity of Hydrogenated Ultra-low Sulfur Diesel Fuel” Energy Sources, Part A, pp. 254-264.

- Lübbe M, Gigler AM, Stark RW, Moritz W (2010), ’Identification of iron oxide phases in thin films grown on $\mathrm{Al}_{2} \mathrm{O}_{3}\left(\begin{array}{llll}0 & 0 & 0 & 1\end{array}\right)$ by Raman spectroscopy and X-ray diffraction” Surface Science No. 604, pp.679-685

- Margoni D (1998), “Fuel lubricity” Industrial Lubrication and Tribology, Vol. 50, pp. $108-118$.

- Morecroft DW (1972), "Reactions of Octadecane and Decoic Acid With Clean Iron Surfaces" Wear, Vol. 18, pp. 333-339.

- Oguz H, Duzcukoglu H, Serafettin E (2011), “The Investigation of Lubrication Properties Performance of Euro-Diesel and Biodiesel” Tribology Transactions, Vol.54, pp.449-456. 
- Qu J, Truhan JJ, Blau PJ, Ott R (2007), “The Development of a 'Pin-on-Twin' Scuffing Test to Evaluate Materials for Heavy-Duty Diesel Fuel Injectors, ’'Tribology Transactions, Vol. 50, pp. 50-57.

- Oláh ZS, Szirmai L, Resofski G (2005), “Micro and Nano Analyses of Wear Scar Surfaces- A Complementary Rating Method to the Evaluation of HFRR Test Results" presented at Fuels 2005, $5^{\text {th }}$ International Colloquium: Fuels, January 12-13 2005, TAE, Esslingen, Germany.

- Spikes HA, Cameron A (1973), "Scuffing as a Desorption Process-An Explanation of the Borsoff Effect"ASLE Transactions, Vol. 17, pp. 92-96.

- Szeri AZ (2005), "Fluid Film Lubrication" Cambridge University Press.

- Wei DP, Spikes HA, Korcek S (1999), “Lubricity of Gasoline” Tribology Transactions, Vol. 42, No. 4, pp. 813-823. 
Table 1: Test parameters for the test conducted on the SRV

\begin{tabular}{|c|c|}
\hline Property & Specification \\
\hline Movement & Oscillatory \\
\hline Applied Load & Steps of $50 \mathrm{~N} / \mathrm{min}$ \\
\hline Stroke & $1 \mathrm{~mm}$ \\
\hline Frequency of Oscillation & $50 \mathrm{~Hz}$ \\
\hline Test Duration & $1 \mathrm{~min} / \mathrm{stage}$ until breakthrough \\
\hline Fluid Temperature & $110^{\circ} \mathrm{C}$ \\
\hline Fluid Volume & Continuous feed rate @ $1 \mathrm{drop} / 5 \mathrm{sec}$ \\
\hline \multicolumn{2}{|l|}{ Test Ball } \\
\hline Material & AISI E52100 steel \\
\hline Hardness & Rockwell C60 +/- 2 \\
\hline Surface Finish $\left(\mathrm{R}_{\mathrm{x}}\right)$ & $0.025+/-0.005 \mu \mathrm{m}$ \\
\hline Diameter & $10 \mathrm{~mm}$ \\
\hline \multicolumn{2}{|l|}{ Disk } \\
\hline Material & AISI E52100 steel \\
\hline Hardness & Rockwell C60 +/- 2 \\
\hline Surface Finish & $0.025+/-0.005 \mu \mathrm{m}$ \\
\hline Diameter & $24 \mathrm{~mm}$ \\
\hline Failure Criterion & $\begin{array}{l}\text { Film Breakthrough } \\
\text { (When } \mu>0.3 \text { ) }\end{array}$ \\
\hline Test Method & In-house \\
\hline
\end{tabular}




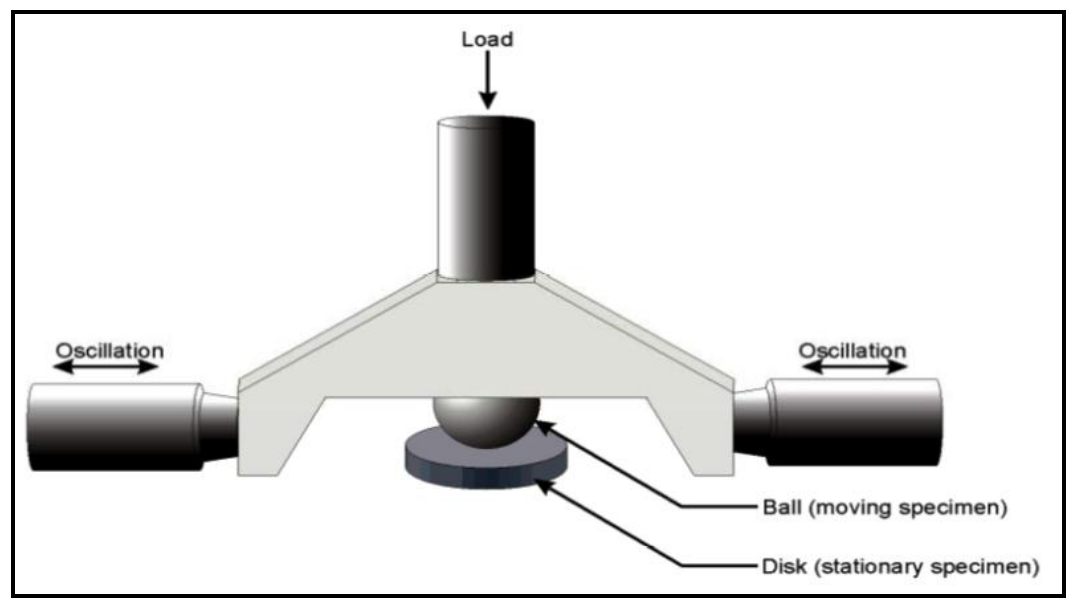

Fig. 1: SRV operating principle

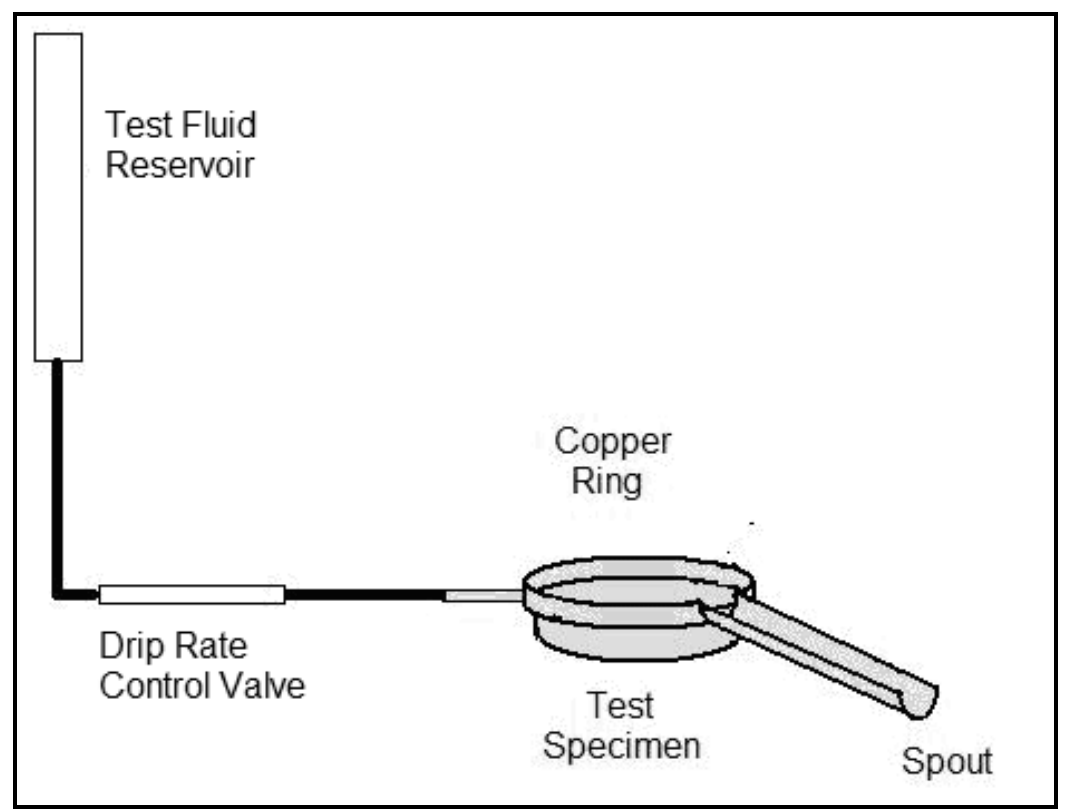

Fig. 2: Feeding system used for the load carrying capacity test of diesel fuels. 


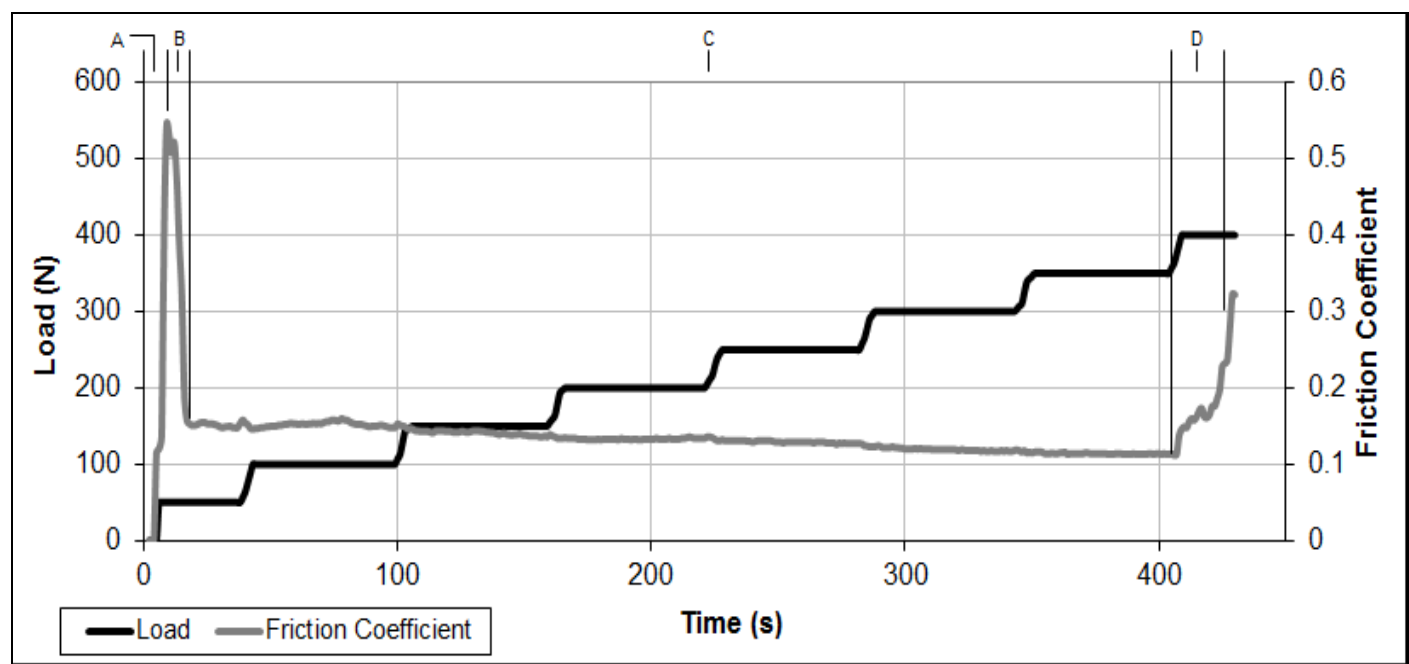

Fig. 3: Change in friction coefficient with time and normal load during a SRV-LCC test (2 000 $\mathrm{mg} / \mathrm{l}$ palmitic acid)

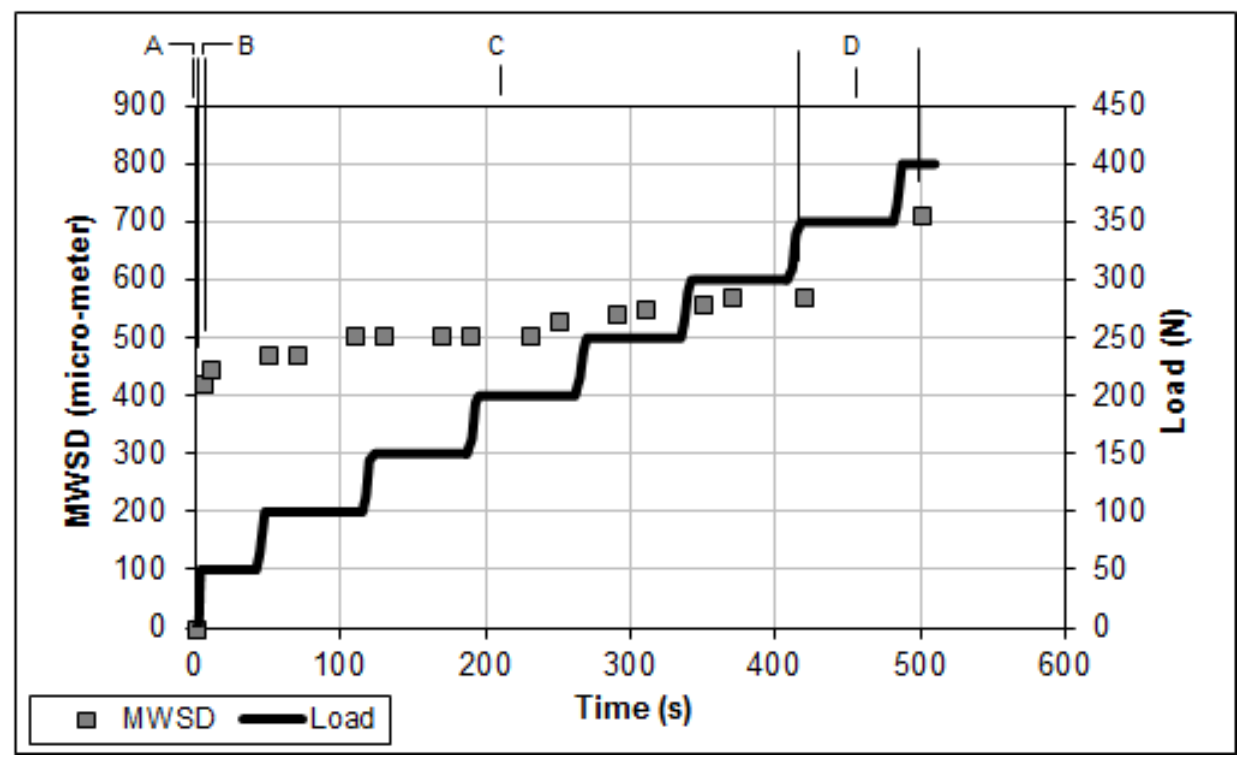

Fig. 4: Change in MWSD with load and time during a SRV-LCC test $(2000 \mathrm{mg} / \mathrm{l}$ palmitic acid) 


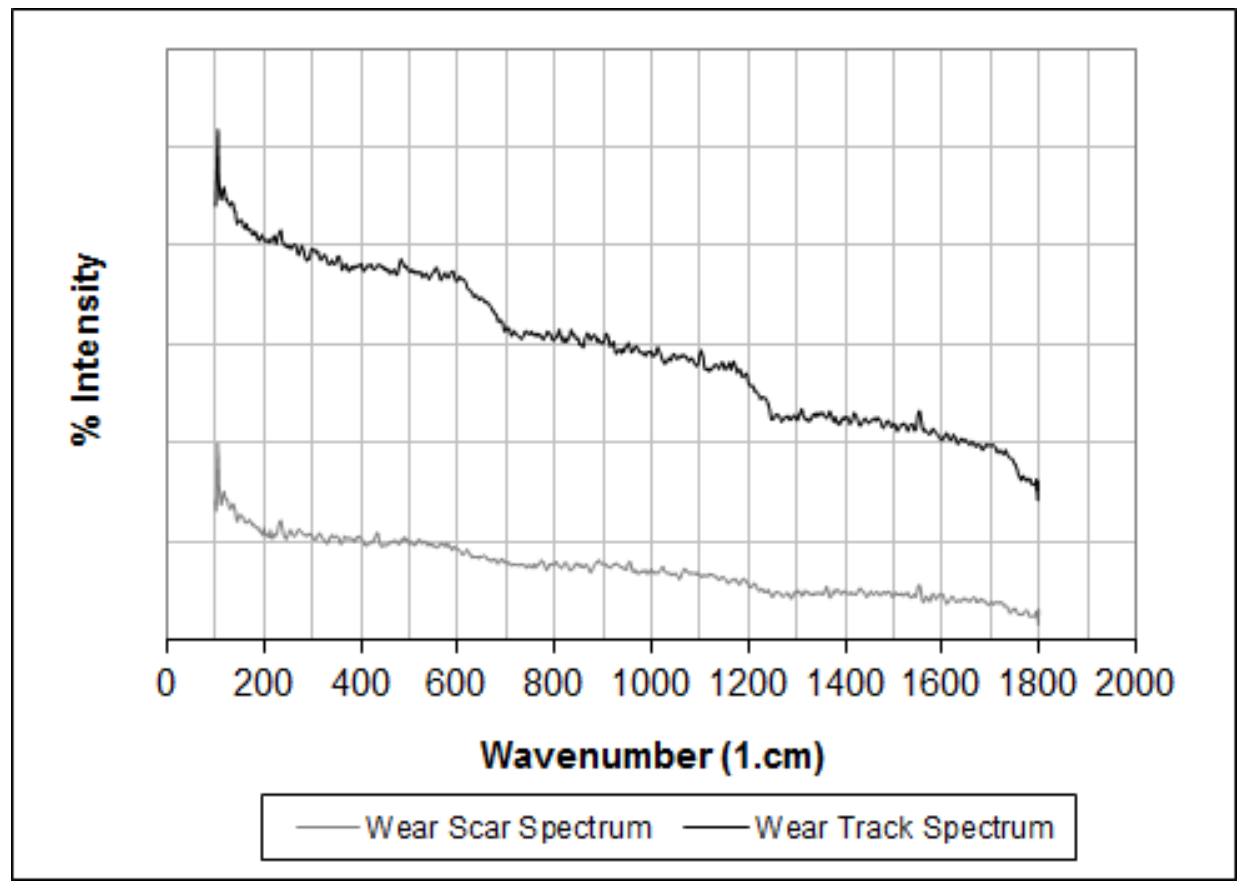

Fig. 5: Raman spectrum obtained on the majority of wear scar and track surface after 5 seconds during a SRV-LCC test (2 $000 \mathrm{mg} / \mathrm{l}$ palmitic acid).
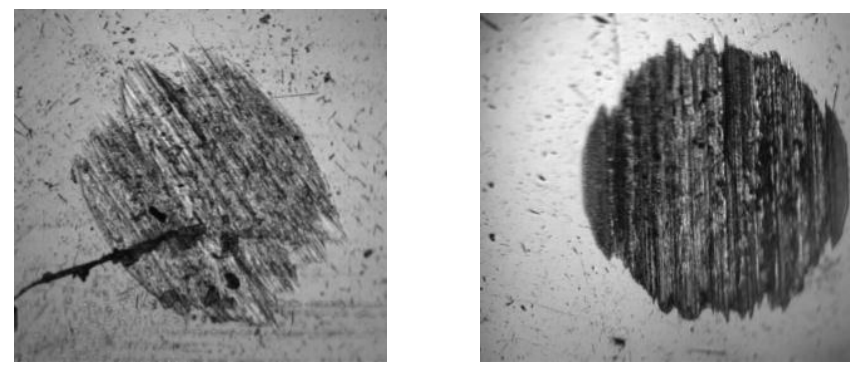

Fig. 6: Wear scar appearance after 5 seconds (left side) and 10 seconds (right side) during a SRV-LCC test (2 $000 \mathrm{mg} / \mathrm{l}$ palmitic acid) (10X magnification) 


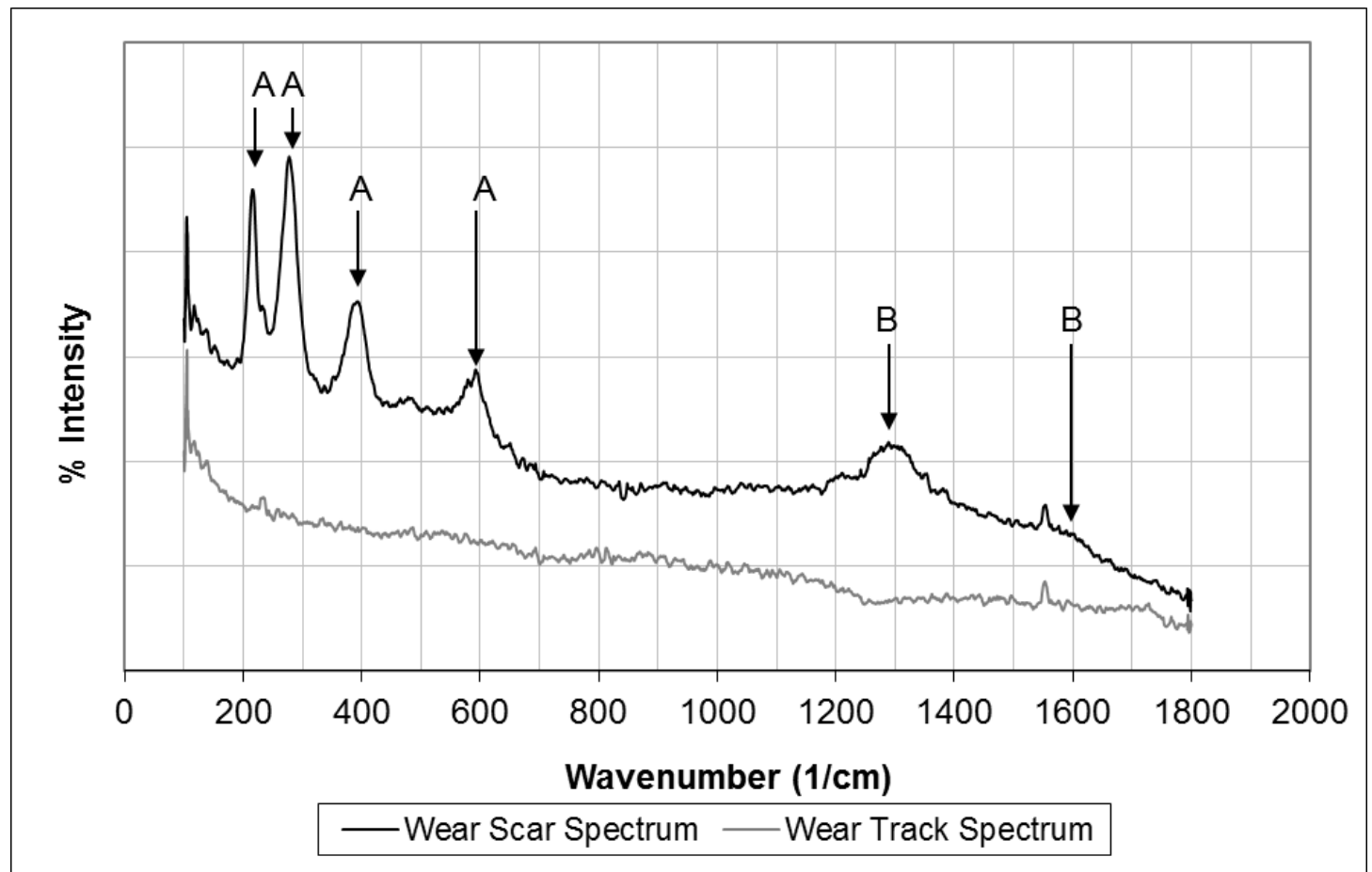

Fig. 7: Raman spectrum obtained on the majority of wear scar and track after 10 seconds during a SRV-LCC test in an air environment (2 $000 \mathrm{mg} / \mathrm{l}$ palmitic acid). 


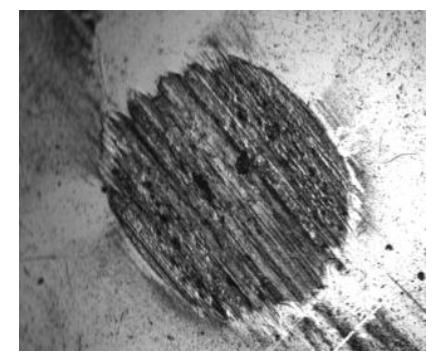

$50 \mathrm{~N}$

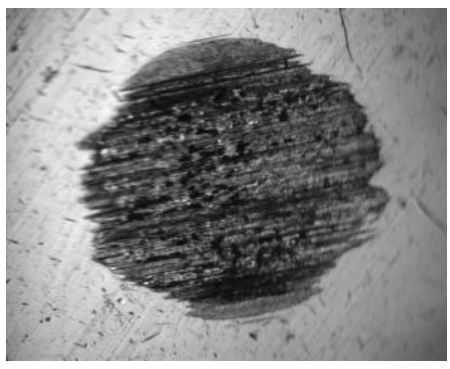

$200 \mathrm{~N}$

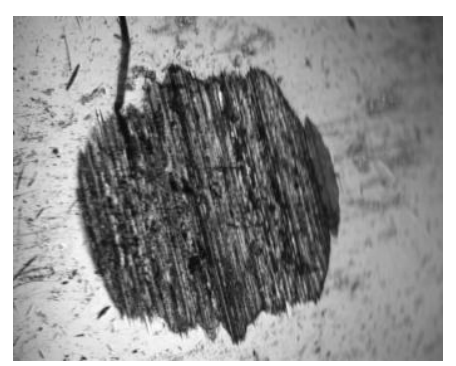

$100 \mathrm{~N}$

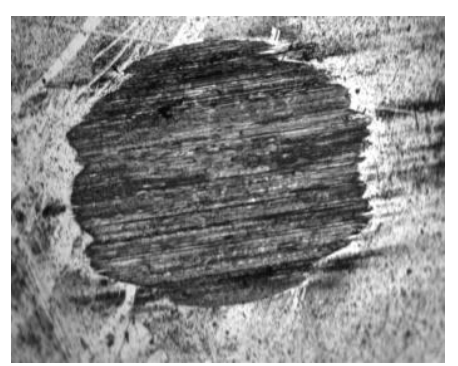

$150 \mathrm{~N}$

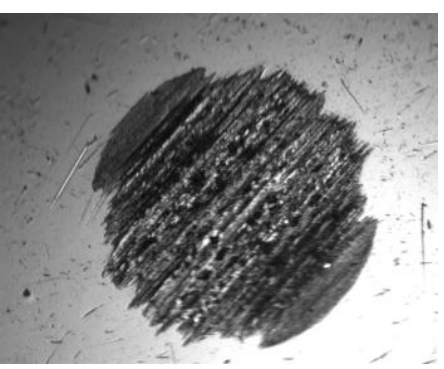

$250 \mathrm{~N}$

Fig. 8: Wear scar appearance at load stages 50 N, 100 N, 150 N, $200 \mathrm{~N}$ and $250 \mathrm{~N}$ during a SRVLCC test (2 $000 \mathrm{mg} / \mathrm{l}$ palmitic acid) (10X magnification) 

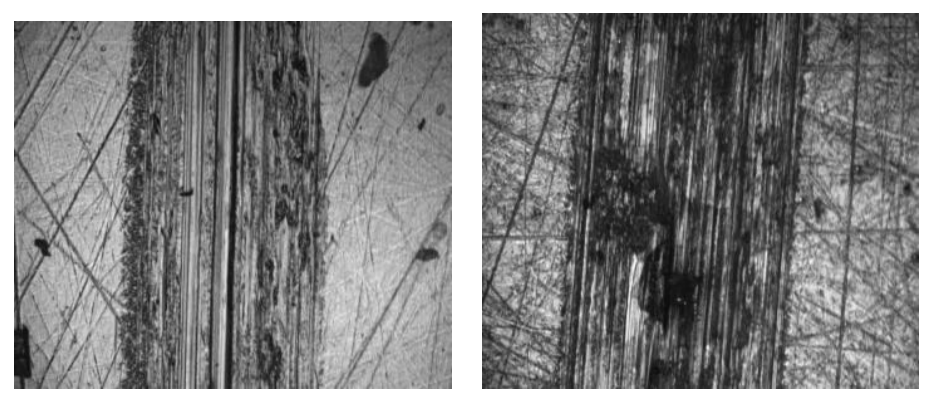

50 N

$100 \mathrm{~N}$

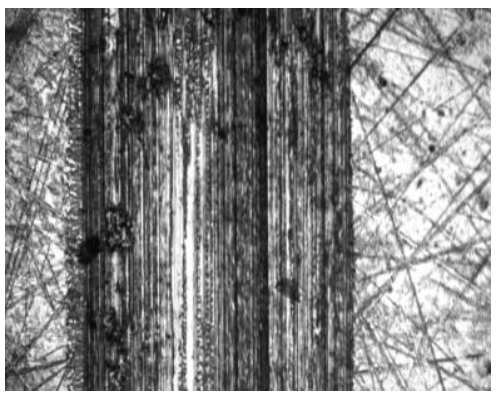

$150 \mathrm{~N}$

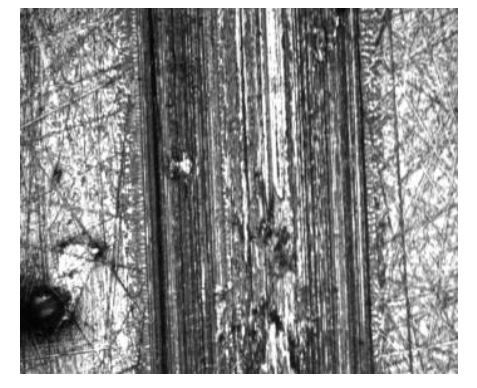

$200 \mathrm{~N}$

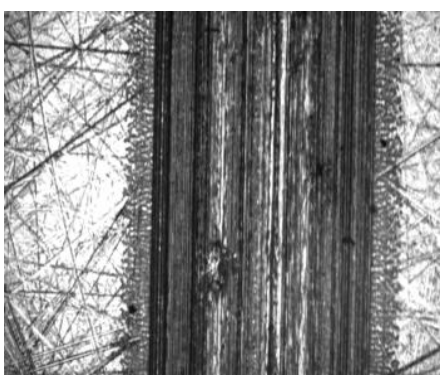

$250 \mathrm{~N}$

Fig. 9: Wear track appearance at load stages $50 \mathrm{~N}, 100 \mathrm{~N}, 150 \mathrm{~N}, 200 \mathrm{~N}$ and $250 \mathrm{~N}$ during a SRV-LCC test (2 $000 \mathrm{mg} / \mathrm{l}$ palmitic acid) (10X magnification). 
$300 \mathrm{~N}$
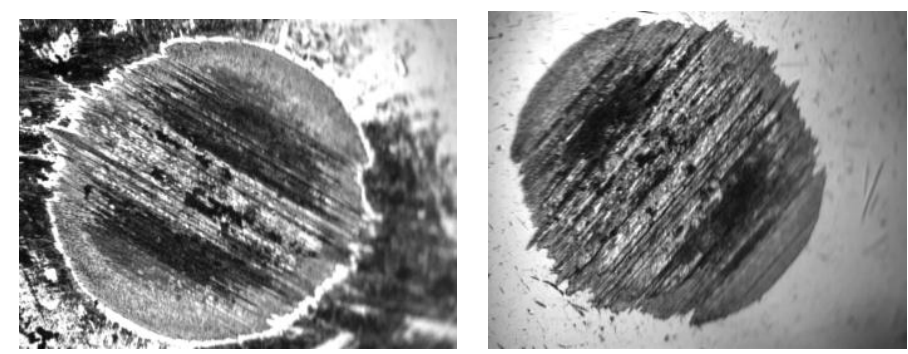

Failure at 400 N

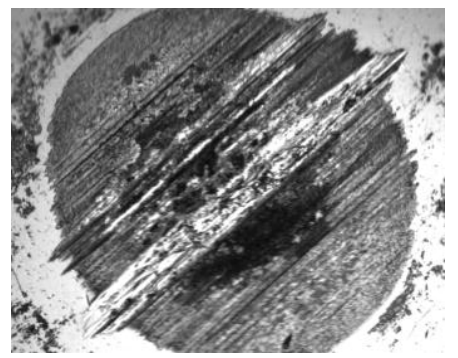

Fig. 10: Change in wear scar appearances as the contact approaches the seizure load during a SRV-LCC test (2 $000 \mathrm{mg} / \mathrm{l}$ palmitic acid) (10X magnification).

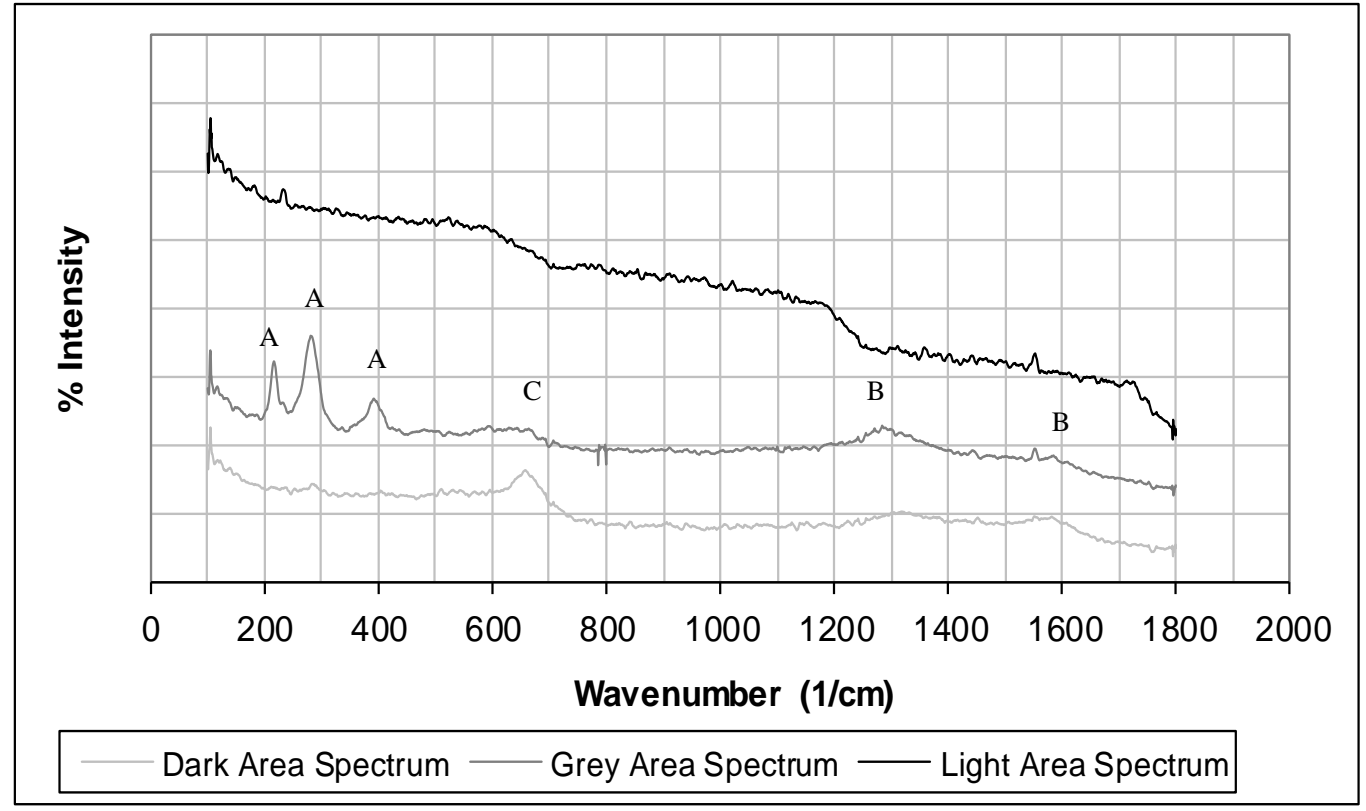

Fig. 11: Raman spectra of the dark, grey and light areas on the wear scar surface at $300 \mathrm{~N}$. 
$300 \mathrm{~N}$

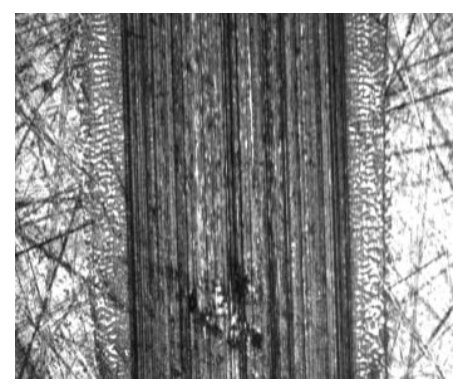

$350 \mathrm{~N}$

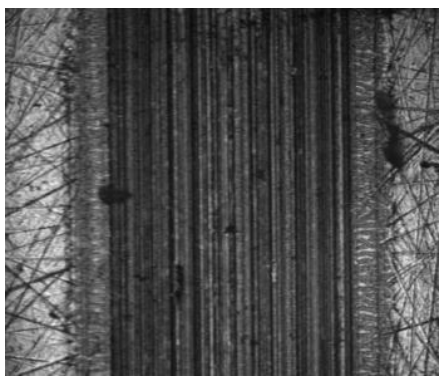

Failure at $400 \mathrm{~N}$

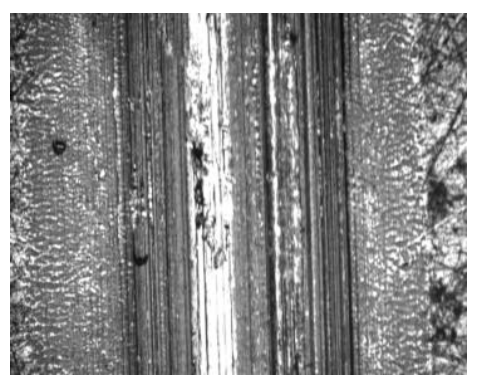

Fig. 12: Change in wear track appearance as the contact approaches the seizure load during a SRV-LCC test (2 $000 \mathrm{mg} / \mathrm{l}$ palmitic acid) (10X magnification).

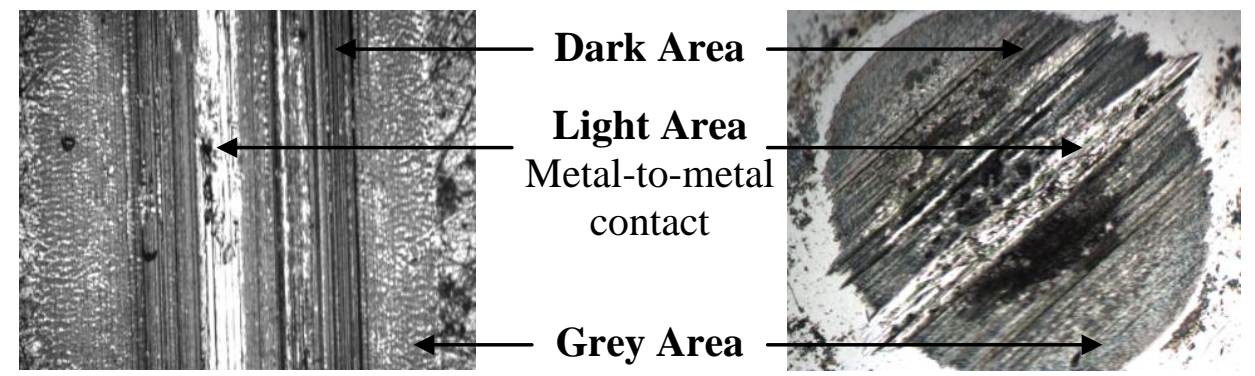

Fig. 13: Appearance of wear scar and track during seizure at $400 \mathrm{~N}$ (10X magnification). 


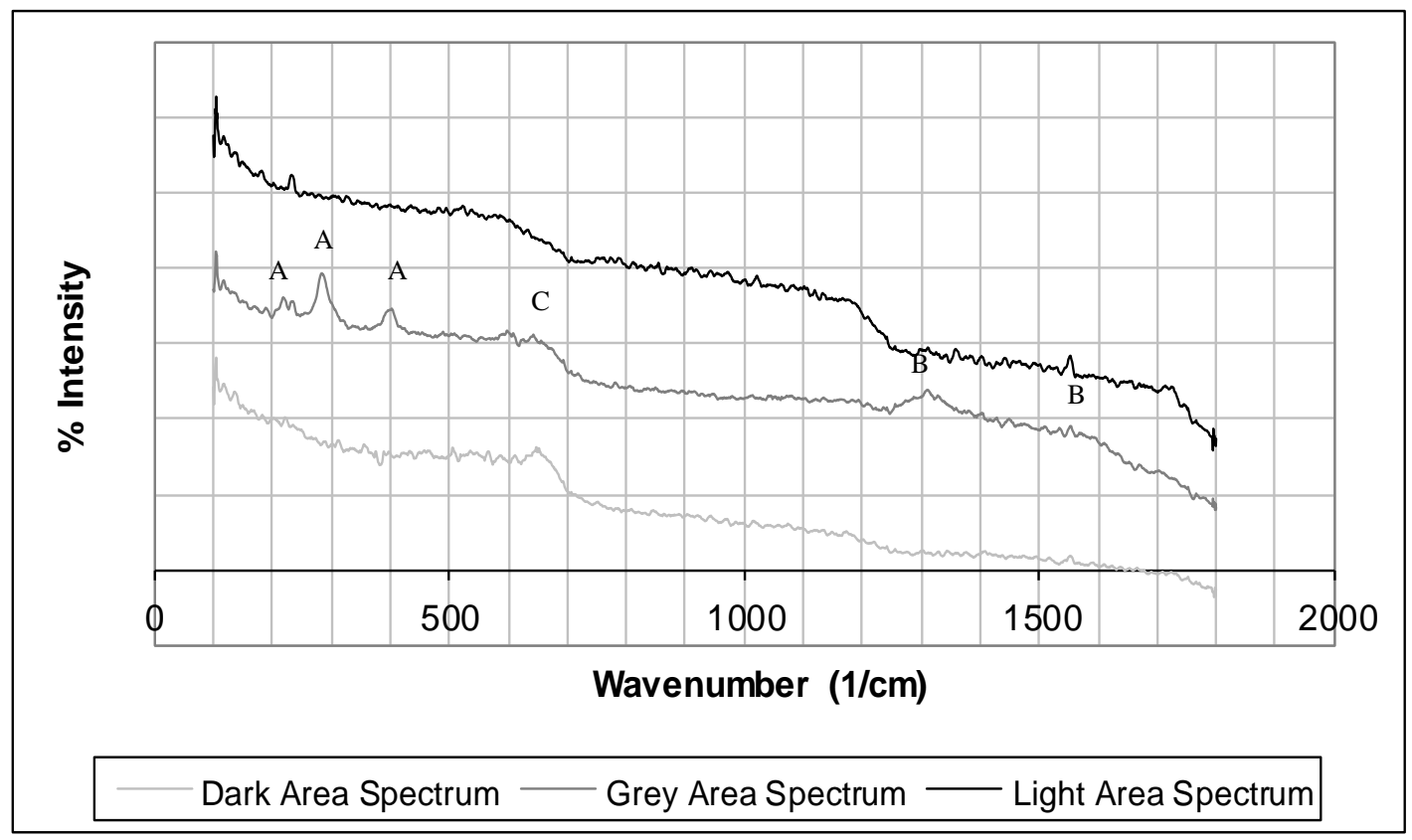

Fig. 14: Raman spectra obtained during seizure at $400 \mathrm{~N}$. 